\title{
A CONTENT ANALYSIS OF THE ONTARIO MINISTRY OF EDUCATION'S MEMORANDUM PPM No.119: DEVELOPING AND IMPLEMENTING EQUITY AND INCLUSIVE EDUCATION POLICIES IN ONTARIO SCHOOLS
}

\author{
By \\ Natalie Royer \\ Bachelor of Arts, Ryerson University, Toronto, 2007 \\ Diploma in Honours in Early Childhood Education, Seneca College, Toronto, 2005
}

\author{
A Major Research Paper \\ Presented to Ryerson University \\ In partial fulfillment of the requirements for the degree of \\ Master of Arts \\ In the Program of \\ Early Childhood Education
}

Toronto, Ontario, Canada, 2013

@ Natalie Royer 2013 


\section{Author's Declaration}

I hereby declare that I am the sole author of this major research paper. This is a true copy of the MRP, including any required revisions.

I authorize Ryerson University to lend this paper to other institutions for the purpose of scholarly research.

I further authorize Ryerson University to reproduce this paper by photocopying or by other means in total or in part, at the request of other institutions or individuals for the purpose of scholarly research.

I understand that my MRP may be made electronically available for the public. 


\title{
A CONTENT ANALYSIS OF THE ONTARIO MINISTRY OF EDUCATION'S MEMORANDUM PPM No.119: DEVELOPING AND IMPLEMENTING EQUITY AND INCLUSIVE EDUCATION POLICIES IN ONTARIO SCHOOLS
}

\author{
@ Natalie Royer \\ Master of Arts Early Childhood Studies \\ Ryerson University
}

\begin{abstract}
Ontario schools have been criticized for maintaining inequitable practices and environments. To combat this inequity, the Ontario Ministry of Education created the PPM No.119: Developing and Implementing Equity and Inclusive Education Policies in Ontario Schools (Ontario Ministry of Education, 2009). In this study, I undertake a content analysis of the policy focusing on the words 'race' and 'parents' in order to explore whether or not racialized children and families, specifically the Black community, may benefit from this policy. Critical Race Theory and a parent engagement framework guided my analysis. The results indicated that this policy may actually exclude students and families, particularly Black students and families, as opposed to creating more equitable and inclusive opportunities. Recommendations are made for promoting anti-racist practices by early childhood educators and teachers and working toward ensuring the accountability of administrators.
\end{abstract}

Keywords: content analysis, race, parents, education, policy, Ontario 


\section{Acknowledgements}

I want to take the opportunity to thank the entire faculty at Ryerson in the MAECS program for their dedication and support throughout the year.

Rene. I would like to thank my best friend, my partner and husband for your unwavering support, and words of encouragement during the entire process.

Barbara, Sylvester, Stephen, Melissa. I would like to thank my family and parents for always supporting me and illustrating unconditional love.

Dr. Rachel Berman. I am indebted to your patience, and support. Thank-you for your words of encouragement throughout the entire process. I couldn't have done this paper without your consistent guidance and sharing of resources. Thank-you for believing in me.

Dr. Marni Binder: Thank-you for taking the time to be my second reader and being available for me throughout the year.

Dr. Kathryn Underwood. I would like to thank-you for your positivity and making analysis less daunting.

Dr. Mehru Ali. I would like to thank-you for showing me that we are indeed all capable.

In addition, I would like to thank my extended family, close friends and peers at Ryerson for their support and motivation during the last year. 


\section{Table of Contents}

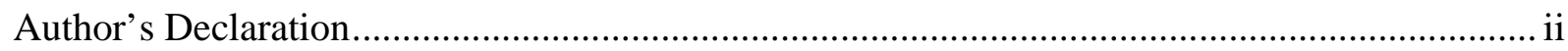

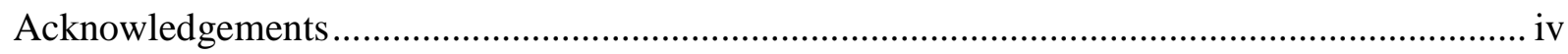

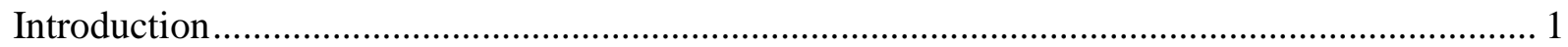

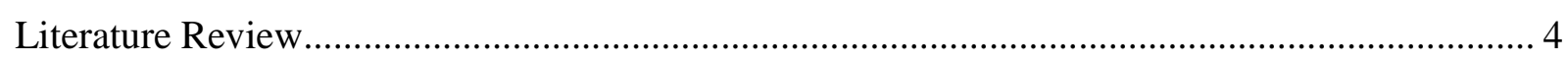

Historical Context Leading to the Introduction of PPM No.119 (2009)................................... 4

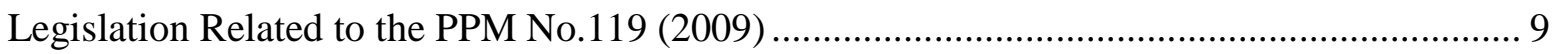

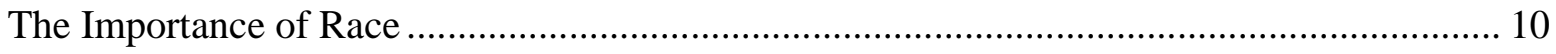

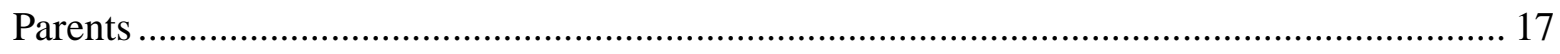

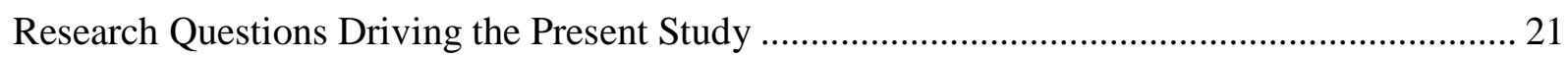

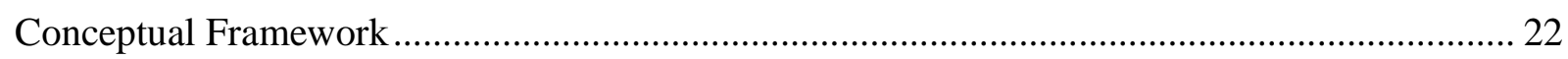

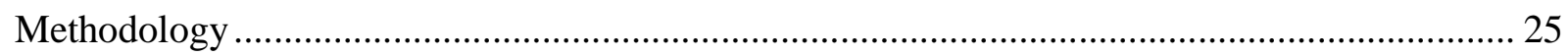

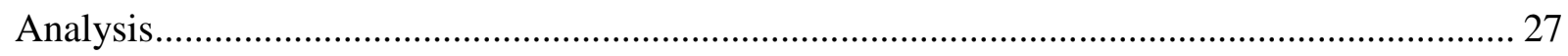

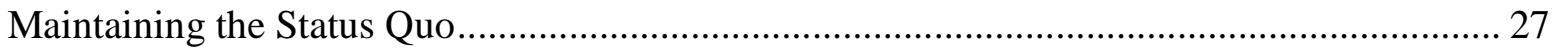

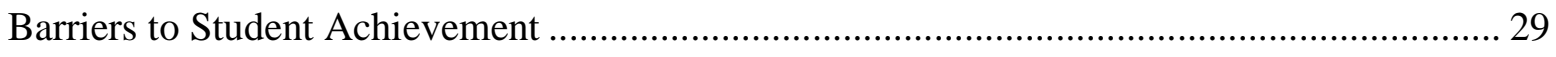

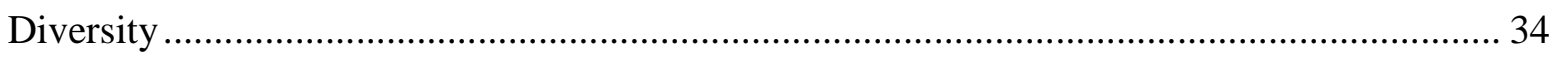

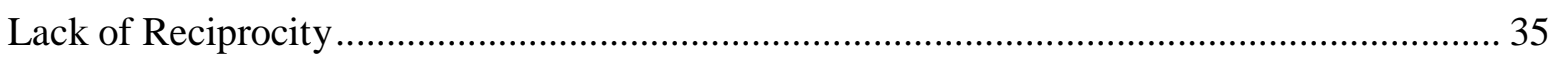

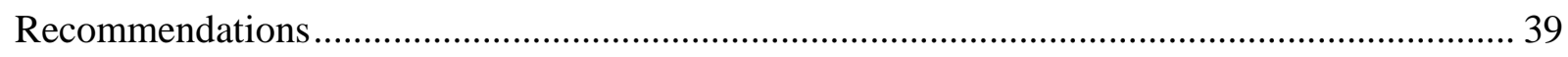

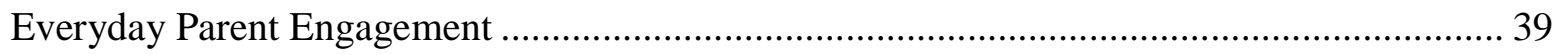

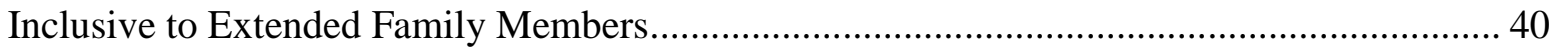

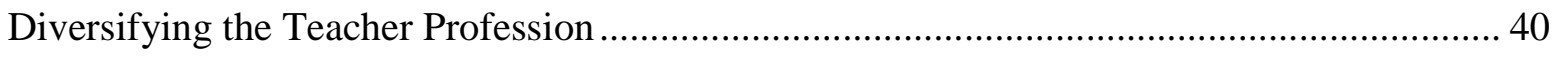

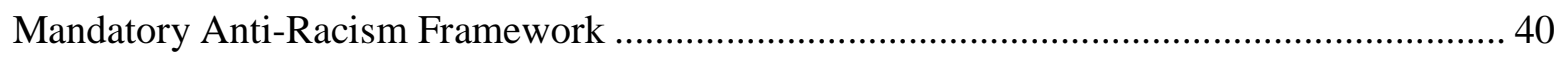

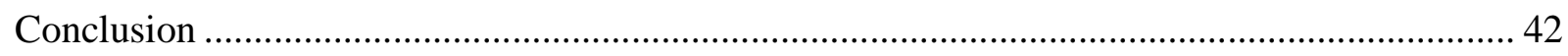

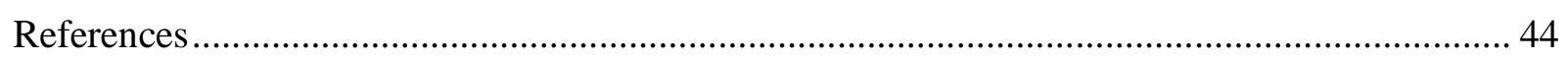

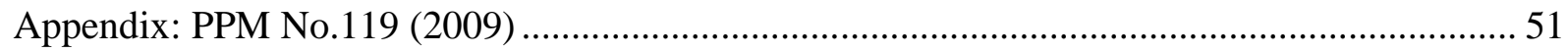




\section{Introduction}

"No institution in society has a greater impact in defining and shaping the lives of young people as does the education system" (Galabuzi, 2008, p.29).

I grew up in Toronto, Ontario, with Caribbean parents who were active in my school life and believed strongly in the school system. Due to this high regard for education, I valued my good grades and rewards as a result of my efforts in school and I felt I was prepared for the world ahead of me. Now, as an adult, I feel disengaged. An apparent disengagement from my real reality (a Black woman in Toronto), I am emerging from a false sense of security that education brought me. With this I feel embarrassed and ignorant of my past and heritage, which has left me feeling detached from my being. Through this paper, I hope to open your mind and stir motivation that will elicit feelings to create social change despite your race, class, gender, and sexual orientation. The structure of schools affects all of us. Although, Canada has a history of coming from a place of exclusion in schools, I still believe that with a consistent commitment from Canadians, we can get to a place that aims to produce anti-racist, inclusive and equitable opportunities for all. However, 'Those who forget the past are doomed to repeat it' (Santayana, 1905, p. 284).

In Ontario public schools, there are consistent issues that involve discrimination and inequities amongst students and parents (Ontario Ministry of Education, 2009a). For the last 30 years, the Ontario Ministry of Education has undergone criticism for their lack of inclusive and equitable practices in school boards across the province (Galabuzi, 2008). Factors such as race, sexual orientation, physical or mental disability, gender, and class can create barriers to success for Ontario students due to systemic issues regarding a lack of equity and inclusion in schools. 
Such factors (i.e. race) can be detrimental to Ontario students and contribute to lower achievement rates among these groups, especially Aboriginals and African Canadian students (Ontario Ministry of Education, 2009b). To combat these equity issues, the Ministry of Education released Memorandum PPM No.119: Developing and Implementing Equity and Inclusive Education Policies in Ontario Schools (Ontario Ministry of Education, 2009c; henceforth PPM No. 119 (2009). In this research study, I will employ content analysis to analyze the presence, meanings, and relationships of particular words embedded in the policy. The following words that will be analyzed are: race and parents. For the purpose of this study, race is defined as a social construction that is visible in all parts of our social life (Ortiz \& Jani, 2010). It is important to point out that race is still seen as a biological concept by many although there is no biological or genetic evidence that race is considered as a basis to determine such things as 'intelligence' (Allahar, 2010). In addition, parent(s) is defined as guardian(s), and family members whom serve as caregivers to children (Ontario Ministry of Education, 2006).

This study is significant to the field of Early Childhood Studies as it comes at a time when Early Childhood Educators have a presence in Ontario schools. Beginning in September 2010, the Ontario Ministry of Education implemented the Full-day Kindergarten Programs (FDK) in Ontario schools (Ontario Ministry of Education, 2006). The FDK is guided by a document mandated by the Ontario Ministry of Education that is based on play-based learning and mandates that kindergartens include a certified teacher and for the first time in the history of Ontario schooling, an Early Childhood Educator (ECE) (Ontario Ministry of Education, 2006). Thus, ECEs will be working alongside kindergarten teachers in a team-based approach and therefore will be working with racialized and marginalized families for the first time in the context of the school system. Alongside teachers, ECEs need to be aware of the implications of 
the PPM No. 119 (2009) and the implicit messages that occur in that policy and how this may affect their practice, as this policy was mandated a year before the FDK was introduced in Ontario Schools.

By disseminating the findings in workshops and conferences, this study will hopefully allow Early Childhood Educators to become cognizant of their practice when working with racialized children and families in the context of the school system in Ontario, particularly in Toronto where racialized students represent $70 \%$ percent of the students in the Toronto District School Board. The TDSB Achievement Gap Task Force Report (2010) states that a racialized group " is a group of people who may experience social inequities on the basis of their perceived common racial background, colour and/or ethnicity and who may be subjected to differential treatment in the society and its institutions" (p.3). For the purposes of this study, I will specifically be looking at the Black community. When referring to Blacks in Ontario, I am referring to those that can trace their roots to Africa. In fact, I will use Blacks and AfricanCanadians interchangeably. Therefore, my overarching research question is as follows: Do racialized (i.e. Blacks) children appear to benefit from the PPM No.119 (2009)?

With this in mind, the next section I will introduce is the literature review. The literature review will highlight the background of the PPM No.119 (2009) in addition to the research that surrounds 'race' and 'parents.' The literature review will demonstrate the importance of race and parents in the lives of Black children and families. 


\section{Literature Review}

\section{Historical Context Leading to the Introduction of PPM No.119 (2009)}

In 1967, many immigrants and people of colour, including Blacks, entered Canada due to changes from the immigration policy that allowed people to enter from places such as Asia and the Caribbean (Young, 1994). Most of these immigrants settled in Ontario, specifically in Toronto. Prior to this time, mostly White ethnic groups migrated to Canada.

In 1971, due to the changes of Canada's demographics and cultural make-up, Canada implemented a Multiculturalism Policy. The goal of this policy was to recognize that Canada was a cultural and plural society that recognized diversity (Henry \& Tator, 2006). The policy became the Federal Multiculturalism Act in 1988. With this policy turning into legislation, many school boards across Canada implemented policies and programs to create an environment that welcomed all cultures into the school and respected the diversity of all students. In addition, there was a push to acquire more diverse teachers in school boards.

However, this multiculturalism policy had critics as well as supporters. Mackey (1999) argues "Multiculturalism as a state policy constructs a concept of a common dominant (English Canadian) culture in which all 'other' cultures are multicultural” (as cited in Henry \& Tator, 2006, p. 285). While some researchers believe multiculturalism is a way to preserve and maintain the dominant group, other scholars reject these claims. Kymlicka (1998), a notable scholar, reacts to this criticism, and argues that there is not enough evidence to demonstrate that multiculturalism prevents immigrants from integrating or leads to any type of ethnic separation. In the end, Black scholars such as Dei and Calliste (2000) argue that multicultural policies "relied on untested assumptions about culture and its transmission" (as cited in Henry \& Tator, 2006, p.213). 
In response to the critiques made regarding multiculturalism, there was pressure from the public to make changes. This, in the mid-1980's, when the New Democratic Party (NDP) was in power in Ontario they issued the Ontario Policy on Race Relations (McConaghy, 1993). According to the Ministry of Education (1987), the purpose of this policy was to illustrate "an active role in the elimination of all racial discrimination, including those policies and practices which, while not intentionally discriminatory, have a discriminatory effect" (as cited in McConaghy, 1993, p.2).

On May 4, 1992, in Toronto, a demonstration that turned into a riot against the treatment of Blacks in the Canadian American Justice system sparked the provincial government still led by Bob Rae, of the NDP, to appoint Stephen Lewis, a former Canadian ambassador to the United Nations, to investigate the riot and review race relations in Ontario (Young, 1994). In his report, Stephen Lewis Report on Racism (1992), he asserted that there was a huge amount of work that needed to be done in regard to inequity and the Black community in Ontario (Paquette, 2001). In his 1992 report, Lewis states

What we are dealing with, at root, and fundamentally, is anti-Black racism. While it is obviously true that every visible minority community experiences the indignities and wounds of systemic discrimination throughout Southern Ontario, it is the Black community which is the focus. It is Blacks who are being shot, it is Black youth that is unemployed in excessive numbers, it is Black students who are being inappropriately streamed in schools, it is Black kids who are disproportionately dropping-out, it is housing communities with large concentrations of Black residents where the sense of vulnerability and disadvantage is most acute, it is Black employees, professional and non- 
professional, on whom the doors of upward equity slam shut. Just as the soothing balm of ‘multiculturalism' cannot mask racism, so racism cannot mask its primary target. (p.2)

Black activist groups complained that no one listened to their interests at the Ministry of Education prior to the Lewis report, although, Paquette (2001) asserts that Lewis did not have sufficient evidence to make such claims and made some judgements based on activist Black groups. However, in response to Lewis' damning report, changes were made to the Education Act for all school boards so as to create anti-racist policies, although most boards did not make any significant changes (McConaghy, 1993).

Due to the lack of changes, and pressure from the Ontario Human Rights Commission, on July 15th, 1993, Dave Cooke, the Minister of Education revealed the government's policy PPM No.119, Development and Implementation of School Board Policies on Anti-racism and Ethnocultural Equity (1993). This policy was created to focus on the need to change school policies that may seem to be racist in nature. Another goal of this policy was for students to appreciate diversity, while rejecting discriminatory behaviour. Although, some researchers still claim that creating this policy came with excessive hesitation (Young, 1994).

A change in political parties played a role in how the policy was to be addressed in the mid- and late-90s. The Progressive Conservative government took over in June 1995, led by Mike Harris, and made lasting changes to policies and practices in Ontario. Harris' changes brought neoliberal policies to Ontario (Segeren \& Kutsyuruba, 2012). Neoliberal policies can be described as economic policies that favour free market enterprise and privatization. In addition, neoliberal policies favour individualism (Young, 1994). A critic of neo-liberalism, Young (1994) argues that these policies served to position education as a way to produce a profitable workforce 
so as to ensure a competitive economy, a goal that tends to compromise students and encourage rampant individualism over community. Not surprisingly, George Dei (2003), a renowned antiracist scholar, points out that during the period of the Harris government, there was a decline in anti-racism initiatives in Ontario.

However, the election of Dalton McGuinty of the Liberal Party in 2003 brought new hope to those seeking equity in schools. He vowed he was committed to education and equity. Hence, a new policy was born, although it took six years after the election (Segeren \& Kutsyuruba, 2012). In June 2009, PPM No.119:Development and Implementation of School Board Policies on Anti-racism and Ethnocultural Equity (1993) was replaced by the Ontario Ministry of Education and Training, with another memorandum: PPM No.119: Developing and Implementing Equity and Inclusive Education Policies in Ontario Schools (2009). The Ontario Ministry of Education is said to believe that this policy would be a way to encourage school boards to develop equity and inclusive education policies to combat the lack of achievement among marginalized children. In addition, this policy was implemented to address issues of bullying and harassment that usually fell under the umbrella of school safety (Segeren \& Kutsyuruba, 2012).

Along with this most recent policy (Ontario Ministry of Education, 2009c), the Ontario Ministry of Education released two other documents that are supposed to work in tandem with the policy as a way to work further toward equity and inclusion. These two documents include Realizing the Promise of Diversity: Ontario's Equity and Inclusive Education Strategy (OEIE) and Equity and inclusive education in Ontario schools: Guidelines for policy development and implementation (Ontario Ministry of Education, 2009a). The purpose of the OEIE is to "support 
a publicly funded education system that gives all students the opportunity to reach their highest potential" (p.1). The OEIE strategy strives to accomplish three goals in Ontario schools. First, by creating shared and committed leadership, which include eliminating discrimination through the identification and removal of bias and barriers. Second, through the creation of equity and inclusive education policies and practices that allows learning environments that promotes respect for all students. Third, via the creation of accountability and transparency regarding the ongoing progress communicated to the Ministry. These goals are meant to assist educators in removing barriers for all children to create a cohesive environment within schools and surrounding communities (Ontario Ministry of Education, 2009b).

Along with these three goals, the Equity and Inclusive Education Strategy (Ontario Ministry of Education, 2009b) outlines three core priorities. It is important to make the distinction between goals and priorities. Goals are possible end results. Priorities are points that need to be pursued right away and are not open to compromise. With this in mind, the core priorities include "high levels of student achievement, reduced gap in student achievement and increased public confidence in publicly funded education" (Ontario Ministry of Education, 2009b, p.5).

To support this strategy, the Ontario Ministry of Education implemented a document called the Equity and Inclusive Education in Ontario Schools: Guidelines for Policy Development and Implementation. The Ontario Ministry of Education (2009a) states that The guidelines provided in this document are designed to help Ontario school boards review and/or develop, implement, and monitor equity and inclusive education policies that will support student achievement, in accordance with the principles and 
commitments set out in Realizing the Promise of Diversity: Ontario's Equity and Inclusive Education Strategy and Policy/Program Memorandum (PPM) No. 119 (2009) (p.7).

\section{Legislation Related to the PPM No.119 (2009)}

Ontario Human Rights Code. The three equity documents work interchangeably with each other and must abide by the Ontario Human Rights Code (OHRC), which promotes fundamental human rights. The Ontario Human Rights Code is a provincial law that works to prevent prejudice, discrimination in jobs and other services while offering everyone equal rights.

Charter of Rights and Freedom. The compilation of the policies that are implemented by the Ontario Ministry of Education (2009b) must adhere to the Canadian Charter of Rights and Freedoms (1982). The Canadian Charter of Rights and Freedoms (1982) enshrines the right for all to be equal "without discrimination and, in particular, without discrimination based on race, national or ethnic origin, colour, religion, sex, age or mental or physical disability" (Equality Rights section, para.15). Every person in Canada has access to such rights and there is an expectation for these rights to be upheld.

Education Act. Along with codes and charters, the Education Act dictates education policies and practices in Ontario. Thus, this act is a fundamental piece of legislation in the province of Ontario. A section of anti-bullying fell under the Education Act, which was a precursor in developing the PPM No.119 (2009) (Segeren \& Kutsyuruba, 2012).

The historical context of the development and introduction of PPM No.119 (2009) sheds light on how policies are influenced and touches on the state of the Black community in recent 
Ontario history. The next section will look at the importance of race and the role it has played in Ontario schooling.

\section{The Importance of Race}

This section will look at the importance of race and the role race plays in the lives of Black students in Ontario Schools. This will be done by giving a historical overview of the segregation of Blacks, along with the construct of race, and then move into the need for antiracist education and educators.

Segregation of Blacks in Ontario schools. In Ontario, there is evidence that discrimination against Blacks in the school system dates back as early as 1828 (Harper, 1997) when Black immigrants were denied entrance to any schools. The Negro Separate School of Act of 1849 allowed Blacks to create their own schools, although the teachers were not trained and the segregated schools were falling apart. Blacks fought for admittance into White only schools until the 1950's, where there was a shift in Canada for integrated schools. The Canadian public system made a decision to "demand the same educational treatment for all" (Harper, 1997, p. 195). Although the last segregated school closed in 1965 (Harper, 1997) and education in Ontario would be available to everyone, Blacks still underperformed in comparison to their White counterparts in academic testing (Brathwaite \& James, 1996) ${ }^{1}$.

Even though there have been desegregated schools in Ontario since 1965, according to Dei and his colleagues (2000), schools remain places where social inequities are played out. The

${ }^{1}$ Aboriginals suffered through residential schools, which were put in place by the Federal government and the Catholic Church in order to eradicate their culture and with the hope they would conform to the dominant culture. A discussion of Aboriginals is beyond the scope of this MRP, but is important to note as their treatment plays a significant role in the history of racism in Canadian education and history. 
dominant discourse of schooling illustrates a power dynamic between those that are from the dominant culture and those who are not. The underlying premise seems to be the dominant way is superior which can be detrimental to Black students.

Achievement gap. Although some researchers believe that the Afrocentric school that currently exists in the TDSB mirrors past segregation of Blacks in schools, many anti-racist scholars as well as some community members argue that it is needed in order for Black children to strive and succeed (Dei, 1996; Galabuzi, 2008). Decades of research illustrate the struggle of Black students in Canadian schools and is a recurring theme when examining the current data released by TDSB (Dragnea \& Erling, 2008). Currently, the failure rate for Black students is $42 \%$ while the failure rate among Black males is almost $50 \%$. Similarly, in a recent report done by Joint Centre of Excellence for Research on Immigration and Settlement, (CERIS) The Ontario Metropolis Centre, shows the same type of figures; $42 \%$ drop out rate for Black students compared to $31 \%$ for White students and $18 \%$ for Asian students (Anisef, Brown, Phythian, Sweet, \& Walters, 2008). These statistics have devastating implications for Black students. Therefore, to combat this disengagement of Black children and their failure rates, the Afrocentric school was created.

Afrocentric school. In 2008, the TDSB set up an Afrocentric Alternative school in Toronto, which is based on an African-centred curriculum and a culturally supportive learning environment. According to Galabuzi (2008), unlike other alternative schools, the Afrocentric Alternative school has non-discriminatory criteria and anyone can attend. However, Galabuzi (2008) still hopes that the Afrocentric School will allow for a process of healing for African Canadians to occur. Healing is needed due to the exclusion of afrocentrism in schools and the systemic racism embedded in school culture. In fact, Dei (1996a) discusses the need for 
afrocentrism in schools to not only address the education needs of Black students, but all students. However, research suggests that Black youth are not in favour of Black-focused schools and many African-Canadians feel that they may be 'labelled' in the eyes of mainstream schools (Gordon \& Zinga, 2012).

Race and class. In Dei's (1996a) study, he raises an important point that not all Blacks are the same and they are not a homogeneous group. There may be different needs of Blacks born in Africa from Blacks born in the Caribbean and Canada. Allahar (2010) discusses Caribbean-Canadian Blacks in a more recent study, but in a political context. Allahar (2010) claims despite the differences in the "Black community" there is a specific homogeneous group among Caribbean-Canadian Blacks. This group consist of those that are unable to cross class lines and move out of poverty. Allahar (2010) refers to this group as the Caribbean diaspora (a group that has been dispersed outside of their homeland). This group is more racialized and reside in certain neighbourhoods. Due to the capitalist nature of Canada, these Blacks in the homogeneous group (Caribbean diaspora) add to the economy by being groomed for menial labour jobs (Allahar, 2010).

Previously, Dei \& Karumanchery (1999), discuss the marketization of education and how Ontario schools facilitate competition between students, which will only serve to benefit the powerful and wealthy members of the dominant culture. Therefore, if there is a shift from a focus on equity to more of a cost-effective approach (a neoliberalist tenet), then marginalized children will continue to fall through the cracks. This claim may be evident in standardized testing, starting in 1996 in Ontario from the Education Quality Accountability Office (EQAO) administered to students across the province in grades three and six. Some researchers claim that these tests, demonstrate a neo-liberal agenda especially since the EQAO was implemented by 
Harris' government more than a decade ago (Segeren \& Kutsyuruba, 2012). This agenda sees students as only individual learners who are pitted against one another in a competition, instead of being part of a community of learners (Dei, 1999).

Race, class and gender. Rooted in feminist scholarship, the promotion of the intersection of race and gender was originally conceived as a way to give Black women more visibility among feminist scholars, due to the fact that the experiences of Black women were left out of the common discourse of 'woman's experience' in feminist literature (Crenshaw, 1989). However, more recently, 'intersectionality' is said to relate to how these oppressions (race, class and gender) mutually intersect with each other (Collins, 2000).

The construct of race and the process of racialization. It is widely accepted by the majority of scholars that race is a social construction, and race-based belief systems are visible in all parts of our social life (Ortiz \& Jani, 2010). For example, Eurocentric norms, which constitute the dominant culture of whiteness, are usually associated with words such as 'achievement' and 'middle class.' However, the ideologies that surround being Black still carry negative connotations such as 'underachievers' and 'lazy' (Ladson-Billings, 1998). Therefore, due to racialization, Blacks are categorized as a group, a group with derogatory social identities.

Racialization includes the stereotypes of Blacks. This is seen with the stereotypes of Black boys. According to James (2012), Black boys are bombarded with the inequitable social structure of schools that emphasize stereotypes that make it difficult for them to excel. Along with school, teachers operate with preconceived ideas about Black boys that are encouraged by media. These stereotypes include lack of discipline, underachievement, and poor academic outcomes. In fact, James (2012) asserts that in Canadian schools, "stereotyping, including the 'at 
risk' designation, operates in a context informed by a multicultural discourse that masks the fact that race matters" (p.485). There is an increasing interest for scholars to conduct research on Black boys. However, research remains scarce on Black girls specifically in Ontario, which may further suggest their subordinate position in society.

It is important to note that many Black scholars assert that it is problematic when White people insist that they do not notice the skin colour of a racial minority; often defined as colourblindness (Morgan, 2011). James (1994) argues that "race is part of the 'baggage' that people of colour carry with them and the refusal to recognize racism as part of everyday values, policies, programs, and practices, is part of the psychological and cultural power of racial constructions" (as cited in Henry \& Tator, 2006, p. 25). These claims by James and others illustrate the need to recognize race in policies.

According to Dei \& Razack (1995), inclusivity in schooling means educational practices that make a genuine effort to include all students by addressing equity issues, in other words, for one, by not engaging in colour-blind practices. Similarly, in Dei, James, Karumanchery, JamesWilson, \& Zine (2000), inclusivity is examined more closely. Dei et al. (2000) claim that inclusivity enhances the learning process as this approach allows children to create a sense of community. In short, equitable and inclusive educational practices can be used to make the learning process cohesive for children and can create a sense of responsibility within their own community of peers (Dei et al., 2000).

Anti-racism in education. As demonstrated in an earlier section of this paper, the discourse of anti-racism has been pitted against the discourse of multiculturalism. As mentioned before, multiculturalism education is designed mainly to teach students about the cultures of 
other people. However, Schick (2010), an anti-racist scholar illustrates in Anti-Racism in Education that although cultural practices may support students in some ways, it is not a solution to the lack of success among many students. In fact, Schick (2010) states that "it is not the presence or lack of culture that has failed students so much as the structural and systematic racism in which student histories, economics and social lives are ignored and/or vilified" (p.53). Hence, she argues for the necessity of anti-racist education.

In addition, anti-racist scholars such as George Dei have written extensively on antiracism along with outlining principles of anti-racist education (see Dei, 1996b). Dei (1996b) argues that anti-racist education is "based on the principle that race, despite the concept's lack of scientific foundation, is anchored in the experiences of racial minorities in society and in the school and that anti-racism is a tool for social change" (as cited in Henry \& Tator, 2006, p.214). Similarly, according to Schick (2010), anti-racist education acknowledges that there are power relations that are evident in everyday practices. Anti-racist education is aware of school discourses that seem to normalize marginalization and White racism. The premise of anti-racist education opposes the view that school discourses are neutral. Therefore, anti-racism objectives require educators to have some clarity in regard to the problems they will be addressing in the classroom and the understanding that their work is not neutral, meaning that the values of the dominant culture are praised, while non-Western cultures and knowledges are devalued (Henry \& Tator, 2006).

Diversifying the teaching profession. In addition to the diverse population in Ontario, there is a call to diversify the teaching profession in order to promote equity and inclusion in the classroom and in order to promote anti-racist practices (Ayepong, 2010). Not only is there the 
need to educate teachers around diversity and inclusion, but there is a need to hire teachers that provide different worldviews. The reason for this is that most teachers are middle-class White women that share Eurocentric perspectives, which can have limitations for students since they will not be exposed to diverse knowledges (Ayepong, 2010).

Due to their membership in the dominant culture, it is likely most teachers will not understand the implications of being racialized. Solomon (1997) demonstrates, through narratives of pre-service teachers that White teachers seem to acquire an identity based on dominant pedagogical techniques, whereas minority teachers acquire an identity grounded in ethnicity and race. The reason minorities are grounded in ethnicity and race is because race is seen as a part of their identity.

Regardless of who is hired, Ayepong (2010) claims that educators and schools need to explicitly name racism to start addressing this social inequity. She makes the case that people in authority need to be accountable for their actions, and that teachers must have ongoing training in anti-racism education. Ageypong (2010) asserts that only by teachers being taught an antiracist framework can they truly create an inclusive curriculum. In essence, an anti-racist framework would not just benefit ethnic and marginalized communities, but would benefit all children.

This section has illustrated the importance of race and the role race plays in the lives of Black students in Ontario schooling. Drawing on the principles of anti-racist education, the argument has been made that in order for Black children to benefit from a policy addressing inclusion and equity, race should be labelled as such and a key signifier. 


\section{Parents}

According to both the Ontario Ministry of Education (2006) and the scholar George Dei (1997), parents/guardians, caregivers and other family members play an important role in the well-being and success of all children in school. This section will illustrate the importance of parent engagement, parents as stakeholders in the PPM No.119 (2009) and the documented voices of Black parents in Ontario schools.

Parent engagement versus parent involvement. According to the Ontario Ministry of Education (2009d), parent engagement is an essential component of Ontario's Equity and Inclusive Education Strategy. In Ontario, Parents in Partnership: A Parent Engagement Policy for Ontario Schools (2010) is a policy that promotes parent engagement within the schools. Unlike the Parent Involvement Policy (Ontario Ministry of Education, 2005), the Ontario Ministry of Education (2010) asserts that the new policy is an effective way to illustrate how parents can be engaged in schools and with their children.

According to Pushor (2007), there is a distinct difference between parent engagement and parent involvement. Pushor claims that the word engagement demonstrates the essential role of the parent in a child's life especially in their school experiences. In contrast to parent engagement, Pushor (2007) asserts that the term involvement allows parents to be involved, but unable to partake in decision-making. Therefore, with parent engagement, there is a sense of reciprocity whereby both schools and families benefit. According to Pushor (2007) parents should always be a part of decision-making because parents are the experts on their own children. When parents are seen to be experts, then they have the ability to be partners in educating their children and can have a strong voice in regard to their children's education. 
This distinction between engagement and involvement could be a basis for why the Ontario of Ministry of Education created the Parents in Partnership: A Parent Engagement Policy for Ontario Schools (2010) as opposed to settling with the Parent Involvement Policy (Ontario Ministry of Education, 2005) which illustrates that an effort by the Ontario Ministry of Education is being made to address constructive criticism from other researchers in regard to their policies (Kovak, 2009). The Ontario based organization People for Education illustrates this exact claim. This organization works to support and advance public education in Ontario's English, French, and Catholic schools. In their report entitled Ontario's Urban and Suburban Schools (2008), they argue that Ontario's public school system should be for all children and not focus on 'at risk' children and that the teaching curriculum should be culturally responsive due to the diversity in Ontario.

Stakeholders in developing the PPM No. 119 (2009). In fact, the People for Education was a stakeholder in developing the PPM No.119 (2009) along with two other groups; the Antiracist Multicultural Network of Ontario (AMENO) and Egale Canada. The AMENO are made up of parents, educators and community members working together to replace barriers for children with disabilities, and working on inclusion for each child. Egale Canada (2005) is a national organization founded in 1986 that advocates for equality among the LGTBQ communities and their families. This group has forced policymakers to implement policies that are inclusive of LGTBQ children and families.

The concerns of Black parents. A number of parent groups in the Black community advocate on the behalf of students as well. According to the Organization of Parents of Black Children, the voices of parents are sometimes the only voices that children have to advocate for 
their needs, especially in racialized communities (Toronto Board of Education, 1988). In 1986, The Consultative Committee on the Education of Black Students in Toronto Schools held a meeting with the Organization of Parents of Black Children. The parents presented their concerns and solutions to the committee with five major themes in regard to their children. These themes included: streaming, discrimination, dropouts, special education and curriculum issues (Toronto Board of Education, 1988). In regard to streaming and discrimination, these parents felt that Black students were streamed into basic level programs deliberately due to their race. They also argued that dropout rates among Black students were increasing and in addition, that Black students were mostly placed in special education classes. Also, these parents believed that there was not sufficient material in the curriculum that illustrated their history and culture.

Dei (1993) illustrated the same concerns through a study on Black/African Canadian parents' narratives, where Black/ African Canadian parents suggested that parent involvement can be difficult to carry out due to history, culture and socio-economic status. These same issues remain of concern today among Black students and parents twenty years later (Dragnea \& Erling, 2008). The literature demonstrates the relevance of parent concerns and why parents should be a partner in their child's education. Rather than being due to any inherent deficiencies as racist beliefs proclaim, these concerns may illustrate the contributing contextual and systemic factors as to why Black students are lagging behind.

Black students are also aware of the importance of having their parents actively involved in their school life. In Dei's (1997) study of interviews with Black students, which addresses reasons for disengagement of Black students in schools, students revealed that parent engagement, is essential for their academic success. 
Finally, it is also important to point out that many Black families may have parents or other involved family or non-family members that should be welcome to play an active role in the lives of students. For example, Carol Stack (1974) illustrates the importance of a holding a broader definition of family in Black communities. In her classic and ground-breaking book, All Our Kin: Strategies for Survival in a Black Community, she claims that Black children and their families have people surrounding them that act as parents, but they are not necessarily blood relatives. She refers to these members in Black communities as 'fictive kin.' These relations are agreed upon between individuals in the community where close friends can be considered 'fictive kin.' She negates the stereotypes that Black families are dysfunctional. Instead, she argues that 'fictive kin' can play active roles in the family and can be a resource for marginalized families. She demonstrates that members close to the family can be seen as parents and play significant roles in the lives of Black children. 


\section{Research Questions Driving the Present Study}

It is apparent from the literature that both 'race' and 'parents' play a significant role in the lives of Black students. Since the PPM No.119 (2009) was introduced to promote inclusion and equity in Ontario schools and Black students are at risk for lower levels of achievement. With a particular focus on the words 'race' and 'parents', my main research question is: Do racialized students, in particular Blacks, appear to benefit from this policy or do they lose out? In order to explore this question, I will pay particular attention to the following subquestions:

a) What are the implications of the way particular words are used or not used in the policy?

b) Does the policy appear to further marginalize certain groups? 


\section{Conceptual Framework}

Based on the review of the literature, two lenses appear to be appropriate to take up in this study; Critical Race Theory and a parent engagement framework. In addition, my experiences as an ECE and Black woman play important roles in my research. Therefore, in addition to the literature review and the two theoretical frameworks, my experiential knowledge is added to further shape my conceptual framework.

\section{Critical Race Theory}

Critical Race Theory (CRT) is based on the premise that race is a social construction and race-based belief systems are visible in all parts of our social life (Ortiz \& Jani, 2010). Derived from civil rights scholarship and critical legal studies (Miller, 2013), CRT is a framework that examines the ways in which racism is practiced across institutions by looking at the power structures embedded in educational policies. These power structures are based on White privilege and further marginalize people of colour (Miller 2013). A colour-blind approach, essentially ignoring race, is an inadequate approach according to CRT (Morgan, 2011).

It is worth noting that although it is not widely discussed in the field of ECE, CRT is a significant lens to include. Early childhood educators can challenge power hierarchies by creating a platform for CRT. In the early years, (Morgan, 2011) argues that the silence can be broken around race and this can be done through age-appropriate lessons implemented by early childhood practitioners. In fact, Morgan (2011) asserts that CRT should be implemented through educational policies and initiatives where early childhood educators along with teachers can join educational committees to make a difference by alerting policy-makers to the importance of CRT. 
In short, CRT takes the position that race is a significant factor of social inequity (Ladson-Billings \& Tate, 1995) and employing the premises of CRT allows researchers to examine racial assumptions that infiltrate our daily lives and can help others to understand these connections (Ladson-Billings, 1998). Critical race theorists assert that there is a need to change and expose racist policies that may further marginalize certain groups and uphold a status quo (Tate, 1997). Since the PPM No.119 (2009) is to be implemented in educational institutions across Ontario--which means it is relevant for ECEs in kindergarten settings--an analysis using the premises of CRT appears to be a sound way to examine how race is positioned in this document.

\section{Parent Engagement}

In addition to CRT, Pushor's framework of parent engagement, as discussed in the literature review, will also be considered when analyzing the PPM No. 119 (2009). A parent engagement framework as outlined by Pushor (2007) posits that parent knowledge is equivalent to teacher knowledge, and promotes a sense of mutual reciprocity between families and schools (Pushor, 2007). Both parents and teachers are part of the decision-making process in a child's life. A child's home and community are considered when examining a child's achievement in school not just what happens at school. Therefore, authentic parent engagement relationships are built on trust and allow a platform for parents to exercise power in their child's schooling. In fact, this framework actively promotes community building and strengthening families (Pushor, 2007).

\section{Experiential Knowledge}

In addition to my theoretical lenses and literature review, I have personal knowledge about working with racialized children in ECE settings that I bring to this study. For the last two 
years, I was an Early Childhood Educator in the Full-Day Kindergarten Program (FDK). As an educator in the program, I was aware of the racialized practices that are evident in kindergarten classes. In addition, I am a person of colour and I can identify being a child of colour attending Ontario schools. I believe that equity-based policies have the power to change the Eurocentric ideologies that plague schools. As a new researcher, conducting a qualitative, non-positivistic study, I believe acknowledging one's biases and beliefs is an important element when conducting a study. My personal experiences as an educator and racial minority combined with my beliefs and knowledge regarding inequities amongst Ontario schools led me to conduct this study on the PPM No.119: Developing and Implementing Equity and Inclusive Education Policies in Ontario Schools (2009). 


\section{Methodology}

\section{Content Analysis}

For this study, content analysis was used as a way of analyzing specific words contained in the PPM No. 119 (2009). According to Hsieh and Shannon (2005), content analysis is defined as "the research method for the subjective interpretation of the content of text data through the systematic classification process of coding and identifying themes and patterns" (p. 1278). This type of analysis is seen as a flexible approach for analyzing text data (Weber, 1990). Indeed, many researchers have used qualitative content analysis due to the flexibility of this research method. Qualitative content analysis allows researchers to classify texts into categories that represent meanings. Both "explicit and inferred communication" (Hsieh and Shannon, 2005, p. 1278) can be represented in these categories.

More specifically, I used both a summative content analysis, and a latent content analysis. In summative content analysis, keywords are derived from the literature review and are identified before and during data analysis. Therefore, this method allows the usage of the keywords to be explored, rather than analyzing the data as a whole (Hsieh and Shannon, 2005). For this study, the words 'race' and 'parents' were drawn from the literature review. These words were quantified by illustrating the frequency of these words in the data. In the latent content analysis, in keeping with CRT and a parent engagement framework, the keywords I explored were 'race' and 'parents.' However, there are many steps to content analysis.

Kaid (1989) states that the sample to be analyzed includes "defining the categories to be applied, outlining the coding process and the coder training, implementing the coding process, determining trustworthiness, and analyzing the results of the coding process" (as cited in Hseih and Shannon, 2005, p.1285). The data that was being analyzed was specifically those phrases 
that consisted of both 'race' and 'parents'. Then from that data, I read and re-read the material to develop categories, which were then grouped into themes (Maxwell, 2005). I used cue cards to assist me visually during this process. Then I coded the data into categories. Along with these steps to increase trustworthiness, credibility and and inter-code reliability, I discussed my coding process with my supervisor. Then, I constructed meanings from the data, which illustrate my interpretations and relationships derived from the categories to create themes, which is a critical step in the analytical process (Weber, 1990).

There are advantages and limitations to using both methods (summative and latent) of content analysis. On the positive side, it can be seen as an unobtrusive method to the phenomenon of interest and also provide insights into the way words are actually used (Babbie, 1992; Hsieh \& Shannon, 2005). However, a limitation to this approach is that it may not account for the broader meanings present in the data. In other words, the broader meanings might not be present in the phrases that include 'race' and 'parents,' which can serve as a limitation.

In short, through a content analysis, I applied Critical Race Theory and a parent engagement framework, as I examined both 'race' and 'parents' to address my overarching research question which is, do racialized (i.e. Blacks) children and families appear to benefit or lose out, or both from the PPM No.119 (2009)? 


\section{Analysis}

It is evident that both the word 'race' —which appears 5 times--and 'parents' —which appears11 times--are used very sparsely throughout the PPM No.119 (2009). These words are considered low frequency words in comparison to high-frequency words that are used in the PPM No.119 (2009) such as 'inclusive' (44 times) and 'equity' (45 times). As stated previously, summative content analysis goes beyond just word frequency and includes a latent analysis, which allows interpretation of the content and meanings of words and text (Hsieh \& Shannon, 2005). The following categories illustrate themes that emerged from the data. An analysis of themes is presented in conjunction with the presentation of themes. These themes include maintaining the status quo, barriers to student achievement, and diversity.

\section{Maintaining the Status Quo}

Consistent with the ideologies of CRT, institutional and educational policies promote ideologies that align with the dominant culture to maintain the status quo of society (LadsonBillings, 1998). These policies can further marginalize people of colour. The PPM No. 119 (2009) states that "Boards will therefore provide opportunities for teachers....to participate in training on topics such as antiracism, antidiscrimination, and gender-based violence, and will provide information for students and parents ....(p.7). This phrase indicates that the board have the expertise on anti-racist education. Black parents that are in the community may have vital information to give on gender-based violence or anti-racism, but it is eliminated due to the hierarchal structure of schools and the power they have over how information is disseminated to parents and the community. For example, parents are unable to share their knowledge with school boards, which eliminates the inclusion of their insights on such topics (for example, antiracism). 
Anti-racist education is to benefit all children (Ageypong, 2010). However, there may be a bias by the board communicating anti-racism to parents; the information may come from the Eurocentric perspective. Along with Ayepong (2010), Dei (2003) argues that an anti-racist and inclusive curriculum is crucial for achieving equity in schools. However, in the PPM No. 119 (2009), staff will take training on these topics, and parents will then be informed by the board. Mandatory on-going training of anti-racist education is not noted and the one-way flow of information with parents in regard to anti-racist approaches demonstrates the lack of interest the policymakers have in implementing authentic anti-racist practices that will benefit all children and families especially Black children.

Due to the fact parent engagement is essential and there is a need for reciprocity between parents and teachers, it is surprising that the PPM No.119 (2009) excludes family members and demonstrates clear boundaries in defining 'parents'. According to the PPM No.119 (2009), parents are defined as "parents/guardians" (p.4). The document does not include any other family members in this definition. In Dei et al. (1997), he discusses the importance of family and community in the lives of Black children and the need for them to work together in schools as a strategy to prevent disengagement of Black children in schools. However, by the PPM No. 119 (2009) not including family members as part of their 'parent' composition, viable family members will be excluded that are considered 'parents' in the Black community (Stack, 1974).

Parents should be seen as an inclusive group that make-up a mosaic of families. By not illustrating a mosaic group by excluding family members can be problematic. However this is not mirrored in all of the Ministry's documents. In the FDK (2006), family members are used to define 'parents' along with 'guardians.' It is disturbing that the PPM No. 119 (2009) narrowly 
define family members as only parents/guardians in this document since the PPM No. 119 (2009) claims it is committed to inclusive and equitable practices. It could be construed that the Ontario Ministry of Education does not value these interactions with family members in older grades just in kindergarten. Unfortunately, children and families that do not follow under these parent 'norms' set by the Ontario Ministry of Education in the PPM No. 119 (2009) will suffer due to such exclusions.

\section{Barriers to Student Achievement}

In the PPM No.119 (2009), the policy recognizes that race is a barrier to student achievement. The first introduction to the word race in the PPM No. 119 (2009) is taken from another document by the Ontario Ministry of Education (2008) that states "Equity and excellence go hand in hand....In a truly equitable system, factors such as race, gender, and socioeconomic status do not prevent students from achieving ambitious outcomes” (p.1). The PPM No.119 (2009) highlights this phrase on the first page, to illustrate what an equitable system truly is. The PPM No.119 (2009) core priorities are the same priorities that are stated in Reach Every Student: Energizing Ontario Education (Ontario Ministry of Education, 2008). The core priorities include high levels of student achievement and reducing the gap in student achievement in both documents (Ontario Ministry of Education, 2008; Ontario Ministry of Education 2009c). Since the belief of an equitable system in the PPM No. 119 (2009) is based on a previous document, it illustrates that the PPM No. 119 (2009) has not created any innovative ideas to define equity although they are aware that race, gender and socio-economic status act as barriers for students, as evident in the continuous lack of engagement and drop-out rates of Black students (Galabuzi, 2008). 
In addition, the PPM No.119 (2009) communicates different meanings of equity that lack clarity. In the PPM No. 119 (2009), the word equity is defined as "a condition or state of fair, inclusive, and respectful treatment of all people. Equity does not mean treating people the same without regard for individual differences" (p.9). The word 'excellence' is clearly not mentioned in the definition, which demonstrates that the PPM No. 119 (2009) lacks clarity of what an equitable system involves, which can be problematic for Black students because the institutional policies in place will likely lack clarity thus not allowing them to have access to equitable opportunities in school. In addition, excellence should not be synonymous with 'equity'; this in itself is troubling. CRT alerts us to the fact that ideologies of excellence are created by those of the dominant culture and is a term so ambiguous it can serve to further marginalize not just Black students but any student that does not perform to the standard of 'excellence' in the eyes of the Ontario Ministry of Education. The PPM No.119 (2009) devalues the word equity by using the word in this way.

In addition, there is an evident lack of clarity in defining inclusion. In the PPM No.119 (2009), inclusion education is defined in the policy as opposed to simply inclusion; “...

Education that is based on the principles of acceptance and inclusion of all students. Students see themselves reflected in their curriculum, their physical surroundings” (p. 9). Inclusion is only mentioned once in the document and not defined as a noun as opposed to inclusive which is used as an adjective and mentioned 44 times. By not defining or deconstructing inclusion, this can be seen as detrimental to students, as it will not be clear to school authorities addressing a policy that is supposedly about equity and inclusion. Instead, it appears that the Ontario Ministry of Education is using buzz words, but not taking accountability. Perhaps, in the hopes that they would never have to explicitly address inclusion or equity since its predecessor, the PPM No.119 
(1993) did not make any substantial changes when it was implemented years ago. Therefore, there is a possibility that school authorities will just take the buzz words at face value and not exercise their due diligence in applying such terms especially when they are used interchangeably with no consistent and clear definition, but more importantly, no proper framework for application.

As previously stated, the PPM No.119 (2009) states "Equity and excellence go hand in hand....In a truly equitable system, factors such as race, gender, and socioeconomic status do not prevent students from achieving ambitious outcomes" (p.1). In this context, it is apparent that the Ontario Ministry of Education focuses on education outcomes. This can further marginalize racialized students. To address the need for equity in education you cannot just investigate educational outcomes but you need to focus on educational access as well. The reason is "educational access is mitigated by disparities centered specifically on race, class and gender" that inform the educational outcomes for certain groups (i.e. Black girls) in schools and these social identifications are mirrored in society (Dei, 1997, p.105). Although the policy discusses additional barriers for students that deal with race, class and gender, which is documented in this section, there is not a specific reference to educational access. Therefore, the focus on educational outcomes in the PPM No. 119 (2009) can further marginalize children who occupy these spaces.

However, further in the document, the PPM No. 119 (2009) does make a point to state "It is now recognized that such factors as race, sexual orientation, physical or mental disability, gender, and class can intersect to create additional barriers for some students" (p.2). This statement indicates that the Ontario Ministry of Education (2009c) is now realizing the 
intersection of factors that act as barriers for students. Contrary to the phrasing in the PPM No.119 (2009), the intersection of race, sexual orientation, physical or mental disability, gender, and class race acting as barriers for students is not new knowledge. The lack of knowledge of the intersection of these barriers has led to exclusion of Blacks in addition to other groups of students. In fact, alternative schooling are options for many students, not just Black students, which I will highlight in the following examples.

Alternative schooling. The Afrocentric School was implemented due to the lack of inclusion of racialized ethnic, groups and the disengagement (i.e. high drop-out rates) among black youth. In hopes of closing the achievement gap, Black parents from the OPBC have been advocating to have an African-centred curriculum since the 1980's (Toronto Board of Education, 1988). However, there is not enough empirical evidence that demonstrates the Afrocentric School will increase student achievement among Black students (Dragnea \& Erling, 2008).

Other alternative schools include the Triangle program, which is supposed to provide a non-homophobic environment for Lesbian Gays, Bisexual and Transgender (LGBT) youth (Galabuzi, 2008). LGBT youth have the ability to earn credits toward their high school diploma in a curriculum includes and celebrates LGBT literature, history and issues. In addition to the Triangle Program, organizations have been pushing for equality among the LGBTQ community in all schools. Egale Canada (2005), a national organization that advocates for equality among the LTBQ communities and their families. Unfortunately, many LGBTQ are victims of homophobic bullying at school and feel excluded and victimized. Given that this type of behaviour is said to be increasing, Egale Canada continues to push the government to implement policies that will be inclusive to LGBTQ students and families. These examples illustrate the 
outcomes for marginalized students when inclusive and equitable opportunities are not provided for not just Black students but all students.

Dei (2003) claims that in order for schools to be equitable and inclusive, 'anti-racism' and 'equity' must be the underlying principles However, if the Ontario Ministry of Education cannot be explicit in their meaning of 'equity' or 'inclusion' then how can school authorities implement the PPM No. 119 (2009) effectively? Unfortunately, all students pay the price.

Race and class. In addition, race and class need to be recognized explicitly with further explanation to school authorities that are expected to implement the PPM No. 119 (2009). Dei et al. (2000) argue due to the political market driven economy in Ontario students are seen as "educational clientele "(p. 270). Therefore, they are expected to be commodities after their graduation. So, if racialized students (i.e. Blacks) are failing at such alarming rates then they will be ill-equipped for a competitive marketplace. Therefore, there is a deeper issue that needs to be addressed. By addressing and deconstructing race and class in their policies, the Ontario Ministry of Education will be able to create a more productive means of how education is delivered to Black students, which will address the needs of all students. Aligned with CRT, as stated earlier, some researchers still believe that the social inequities that are embedded in Ontario schools are purposely in place to prepare Black (i.e. Black diaspora) students to work in menial and lowpaying jobs (Allahar, 2010).

In this context, even though intersectionality is not explained; the PPM No.119 (2009) still states that the intersection of these factors (race, class and gender) creates additional barriers for students. In addition, the PPM No. 119 (2009) appears to imply that the intersection of these 
factors may be responsible for students performing poorly, as opposed to other factors (for example, school system, school climate).

The PPM No. 119 (2009) needs to further explain the intersectionality of race, class and gender. Dei (1997) discusses the intersection of race class and gender and how this creates a subordinate position of Black students, especially in Black girls. In addition, Black girls are not only marginalized at school by their peers but in society as well. Thus, the policy makes no tangible connection to the intersection of race, class and gender and the implications for Black female students, or Black LGBTQ students, and so forth.

\section{Diversity}

Race is used as part of the definition of diversity in the appendix, No.119 (2009) states "the dimensions of diversity include, but are not limited to, ancestry, culture, ethnicity, gender, gender identity, gender expression, language, physical and intellectual ability, race, religion, sex, sexual orientation, and socio-economic status" (p.9). Again, these definitions are created by an educational lens that mirror Eurocentric ideologies, which dismiss the visibility of race and the impact it has as a visible human attribute. Race is listed along with sexual orientation and culture, which are non-visible attributes. Since diversity is a current theme in recent Ontario education policies (Segeren \& Kutsyuruba, 2012), then it is necessary not to make diversity such a broad term and explain the differences between visible dimensions of diversity and non-visible dimensions (not visible to the human eye) of diversity in order to promote the inclusion of racialized children and families.

In addition, The Ontario Ministry of Education is cognizant that they serve diverse parents. The PPM No. 119 (2009) declares that "Boards should expand upon their outreach efforts in order to foster new partnerships that engage a cross-section of diverse students, parents, 
staff, community members, and various organizations, including business groups (e.g., business education councils)" (p. 6). From this example, parents are acknowledged as a diverse body and a group that board authorities should engage with.

Even though the policy may strive for diversity, it manages to still uphold capitalist ideologies; this is evident in the data. The policy states that "The board's work force should reflect the diversity within the community so that students, parents, and community members are able to see themselves represented" (p.5), which leads one to believe that families will be able to see themselves represented in the school. However, the policy does not mandate what roles in the schools that must be represented to illustrate the diversity among the community. Thus, families may see themselves in jobs that are undesirable.

\section{Lack of Reciprocity}

According to the PPM No.119 (2009), the policy supports 'active engagement' of parents although the policy still pushes 'consulting' with parents instead of illustrating a sense 'reciprocity' or at least promoting collaboration with parents. There are three clear examples of consultation with parents. To illustrate an example of this claim, the PPM No. 119 (2009) asserts "When reviewing or developing their equity and inclusive education policy, boards are expected to consult widely with students, parents, principals..." (p.4). Consultation refers to a power imbalance; a 'consultation' is done usually to benefit the weaker party. In contrast to consultation, Pushor (2007) discusses reciprocity and states "rather than with the mindset of charity, privilege or expert knowing, acting in reciprocity reflects a relational and caring engagement in initiatives deemed important by and for parents and families" (p.8). There is a clear need to move beyond consultation with parents to a place of reciprocity which will allow 'parent engagement' to truly happen. 
The policy PPM No. 119 (2009) discusses the active engagement of parents and community members with the school board. This suggests that parents can be seen as active members in schools. However, teachers are not specifically acknowledged as having active engagement with parents the policy refers to active engagement with the school. In addition, active engagement is referred to again in the PPM No.119 (2009) which states that "Schools and boards will continue building their capacity - with the active engagement of parents and school community partners - to create and sustain a positive school climate that supports student achievement and well-being" (p.6). Although, the above examples promote engagement with parents, there is no distinction of teachers having active engagement directly with parents specifically, which can be problematic because teachers are not mandated to have authentic 'parent engagement' interactions. In fact, 'parent engagement' is not referred to explicitly. Thus, there is no accountability for teachers to have ongoing dialogue with parents. CRT can shed light on the implications for Black parents created by the lack of reciprocity with teachers. CRT would highlight that Black parents who are unable to navigate the system due to their marginalized position in the eyes of institutional policies can feel further marginalized in parent-teacher and parent-school interactions.

The need for visibility of 'race' and 'parents.' Through the lens of Critical Race Theory, it is readily documented that race is a social construction that infiltrates the daily lives of many racialized children and families (Ortiz \& Jani, 2010, Ladson Billings 1998). LadsonBillings (1998) claims “Despite the scientific refutation of race as a legitimate biological concept and attempts to marginalize race in much of the public (political) discourse, race continues to be a powerful social construct and signifier" (p.8). Since it is quite evident that race has no biological basis, the achievement gap is more troubling and supports other research along with 
relevant parent concerns that highlight the highly problematic and inequitable nature of the current Ontario education system (Dei, 1997, Galabuzi, 2008; Toronto Board of Education, 1988).

Policies need to deconstruct race by highlighting the implications for students of colour when schools do not exude equity and inclusion instead of just listing it as another barrier of student achievement, and illustrate the implications of the oppressions of race, class and gender when intersected. If not, then policies can be misunderstood by school boards who will be implementing these policies in their schools, which can serve to further marginalize Black children and families.

In addition, as the research shows, parents have a level of expertise regarding their children that cannot be replicated by teachers, and they should not be treated as consumers (as they are in a neoliberal discourse) but rather as equal partners (Dei and Karumanchery, 1999). This should be the case for not just Black parents but all racialized parents. In fact, racialized parents need to be part of the education system due to the systemic barriers that are currently in place at institutional levels (Jones, 2002).

Notably, under the three goals of the equity and inclusive education priorities included in the PPM No. 119 (2009), the terms both race and parents are non-existent. Ignoring these terms under the three main goals of the equity and inclusive strategy illustrates the invisibility of Black parents as well as other marginalized groups. Therefore, examining these words in the context of the PPM No.119 (2009) using CRT and a parent engagement framework demonstrates a loose notion of diversity as opposed to focusing on clear and explicit way inclusive and equitable 
practices can be implemented and promoted among Black children and families in the PPM No. 119 (2009).

Although, the Parent Engagement Policy (2010) is a specific policy aimed toward parents, the current PPM No. 119: Developing and implementing equity and inclusive education policies in Ontario schools (2009) is a completely different policy. Since the PPM No. 119 (2009) aims at inclusion and equity, the inclusion of parents should be explicit just as labeling race/racism should be explicit (Ageypong, 2010). Although a major limitation in this study is that it is based on one document, this content analysis can still give insight regarding how to make substantial changes that will benefit all students. With this in mind, I will introduce recommendations regarding how racialized and marginalized children and families can be more visible in Ontario schools, which could hopefully lead to a more equitable system. 


\section{Recommendations}

In policies, language use is a place where we can examine who is silenced and who is dismissed. Policy makers need to explore conversations about race and provide ways to be inclusive to all parents. Such conversations about race should be visible in policies, which will transcend into classrooms by the encouragement of the administrators. Hopefully, educators will be inspired to have deeper conversations and explore racial issues that usually go unnoticed in daily classroom routines (Brown et al., 2010).

\section{Everyday Parent Engagement}

All children need to feel competent and worthy (Dei et al. (2000). In a child's life at school, early childhood educators, teachers, and administrators can influence these feelings by encouraging parents to play a part in decision-making. Flexibility needs to be given to parents to increase access to those parents that are hard to reach due to economic constraints and schedules. The decisions that I am referring to are decisions that will impact children's lives for years to come and go beyond the common practice of parent involvement strategies that involve inviting parents on a school trip. The voice of parents should be prevalent in any policy that is committed to equity and inclusion. This means framing parents as experts and facilitating a platform where they can showcase their expertise and facilitating consistent parent collaboration which may involve different channels of communication (i.e. phone calls, meeting in neutral places, etc.) as opposed to depending on surveys for feedback as noted in the PPM No.119 (2009). Hence, this would create a movement to ensure parent engagement and ensure reciprocity is alive in Ontario schools. 


\section{Inclusive to Extended Family Members}

According to Dei et al. (1997), specific care must be taken to include all parents. Moreover, policies need to include extended family members. Indeed, in many communities, extended family members are considered parents (Stack, 1974). Educators should be cognizant that parents can imply extended family members as well. In addition, teachers may benefit by attending meetings in certain communities to gain knowledge about communities and build meaningful relationships. These are examples of reciprocity and power sharing between educators and parents and reflect Pushor's (2007) notion of 'parent engagement'.

\section{Diversifying the Teacher Profession}

The faculties of education in Ontario need to diversify the students they accept. In addition by ensuring minority teachers are admitted to the school board, children will have the ability to be exposed to an array of worldviews that will give them an informed connection to issues that are relevant to them. The Ontario Ministry of Education must mandate this and ensure these types of representations are happening at Ontario schools.

Along with hiring minority teachers, components of certification for teaching should include working with a 'real' racialized family to fulfill graduation requirements. This may be even more plausible since they are extending pre-service programs from one year to two years in Ontario (Leck, 2013). By extending the teacher's education process and training, an anti-racist framework is feasible.

\section{Mandatory Anti-Racism Framework}

The Ontario Ministry of Education must overhaul the curriculum and mandate anti-racist training. Researchers have illustrated anti-racist principles that can be used as a guide for this training (see Dei, 1996b). Also, administrators need to demonstrate accountability by ensuring 
teachers and educators are held responsible if they do not attend the series of classes on antiracism whether it is pay-related or evaluation related and implement mandatory follow-ups to ensure anti-racist practices are taking place in the classroom. Teachers receive emphasis in these recommendations due to their daily first-contact with children, which puts them in the position to be true change agents. I am aware it takes time to change attitudes. However, accountability must be taken by administrators and policy-makers to enlist such changes. These changes must happen to evoke a change in school culture that will be long lived. 


\section{Conclusion}

In conclusion, this paper sought out to address if Black children and families would benefit from the PPM No. 119 (2009). It is apparent that the terms 'race' and 'parents' need to have more visibility in this policy in order to be inclusive to Black children and families. These findings suggest that this policy is still committed to optimizing institutional power and further marginalizing Black children and families by not including accountability and mandatory requirements. Although, the Ontario Ministry of Education claims the OEIE is Realizing the Promise of Diversity, which acts as a prefix of the OEIE, and working towards diversity on a broad level, which is still a step in the right direction. However, the Ontario Ministry of Education is still exercising the power of maintaining the status quo by ignoring race and the dialogue that goes along with discussions regarding the social construction of race. By doing this, the PPM No. 119 (2009) is attempting to eradicate the voices of marginalized and racialized families. If we cannot have race deconstructed at the systemic level to illustrate progress of the Ontario school system then maybe the Ontario Ministry of Education are taking steps backwards as opposed to forward. This disregarding of Black parent expertise and the lack of apparent interest in addressing race illustrates that Ontario mandated policies are unable to move the dialogue in such a way to address the intersection of social identities such as 'class' as well which is only stated once in the PPM No. 119 (2009). This demonstrates a need for future analysis of education policies in regard to the constant oversight of poverty and the connection of class to achievement in schools. Allahar (2010) illustrates the connection of poverty to racialized communities, which suggest that Blacks can be 'raced' and 'classed' (p. 75). These dismissive actions to people of colour is troubling since there is a broad amount of research that illustrates that Black children are less engaged and failing at alarming rates. 
Perhaps, due to the political agenda of Canada, which implicitly endorses social inequality, an element of a capitalist society (Allahar, 2010), the Ontario Ministry of Education may be creating a type of exclusion mirroring an implicit undertone of the overt discrimination against children of colour implemented more than a century ago. Implementing a policy such as the PPM No. 119 (2009) can be deceiving and the present undertone which further marginalize racialized children and families can be disguised using buzz words such as inclusion and equity, which the analysis revealed lack clarity and consistency. In addition, the Ontario Ministry of Education is not taking accountability or implementing consequences to ensure implementation is conducted, which emphasizes that the PPM no.119 (2009) may not serve any new purposes from its predecessor, the PPM No.119 (1993). Therefore, those that are from the dominant culture will continue to succeed in a school system that is orchestrated by power dynamics and wealth leaving marginalized and racialized children behind. There is still hope that the Ontario Ministry of Education will take more accountability and make the necessary changes to provide an anti-racist and equitable education system that will be deemed inclusive to all students. It is critical that ECEs understand the implications of ignoring such social issues and be cognizant of the compounding barriers that Black children face. However, if changes do not happen and Ontario citizens seek a school system to benefit all children and families, then we are not in need of an education reform but an education revolution. 


\section{References}

Allahar, A. L. (2010). The political economy of 'race' and class in Canada's caribbean diaspora. American Review of Political Economy, 8(2), 54-86.

Anisef, P., Brown, S.R., Phythian, K., Sweet, R., \& Walters, D. (2008, June). Early school leaving among immigrants in Toronto secondary schools. CERIS Working Paper No. 67.

Agyepong, R. (2010). Rethinking anti-racism and equity education: Issues of curriculum and development of teachers. Our Schools/Our Selves, 19, 75-85.

Babbie, E. (1992). The practice of social research. New York: Macmillan.

Brathwaite, S. K., \& James, E. C. (Eds). (1996). The education of African Canadians: issues, contexts, expectations (pp.13-31). Educating African Canadians. Toronto: James Lorimer \& Company Ltd.

Brown, S. A., Souto-Manning, M., Laman, T. (2010). Seeing the strange in the familiar: Unpacking racialized practices in early childhood settings. Race, Ethnicity and Education, 13(4), 513-532.

Canadian Charter of Rights and Freedoms, s 2, Part I of the Constitution Act, 1982, being Schedule B to the Canada Act 1982 (UK), 1982, c 11.

Retrieved from

http://laws-lois.justice.gc.ca/eng/const/page-15.html

Collins, P. H. (2000) 'It's all in the family: Intersections of gender, race, and nation', (pp. 156-176) in U. Narayan and S. Harding (eds) Decentering the center: Philosophy for a multicultural, postcolonial, and feminist world. Bloomington: Indiana University Press. 
Crenshaw, K. (1989). Demarginalizing the intersection of race and sex: A Black feminist critique of antidiscrimination doctrine, feminist theory, and antiracist politics. University of Chicago Legal Forum, 139, 139-167.

Creswell J. (2003). Research design: qualitative, quantitative and mixed methods approaches. 2nd ed. Thousand Oaks, CA: Sage.

Dei, G. J. (2003). Communicating across the tracks: Challenges for anti-racist educators in Ontario today. Orbit, 33(3), 25.

Dei, G. J. (1996a). The role of Afrocentricity in the inclusive curriculum in Canadian schools. Canadian Journal of Education / Revue canadienne de l'éducation. 21(2), 170186.

Dei, G.J.S. (1996b). "Basic principles of anti-racist education". In anti-racism education: Theory and practice. Halifax, N.S.: Fernwood Publishing, pp. 25-49.

Dei, G. J. (1993). Narrative discourses of Black/African-Canadian parents and the Canadian public school system. Canadian Ethnic Studies, 25(3), 45-65.

Dei, G., \& Calliste, A. (2000). Power, knowledge and anti-racism education: A critical reader. Halifax: Fernwood.

Dei, G. J., James, I., Karumanchery, L., James-Wilson, S., \& Zine, J. (2000). Removing the margins: The challenges and possibilities of inclusive schooling.Toronto: Canadian Scholars Press.

Dei, G. J., \& Karumanchery, L. L. (1999). School reforms in ontario: The marketization of education and the resulting silence on equity. Alberta Journal of Educational Research, 45(2), 111-131.

Dei, G. J. S., J. Mazzuca, E. McIsaac, and J. Zine, J. (eds.) (1997). Reconstructing 
"Dropout": A critical ethnography of the dynamics of Black students disengagement from school. Toronto: University of Toronto Press.

Dei, G.J. \& Razack, S. (1995). Inclusive schooling: An inventory of contemporary practices designed to meet the challenge of a diverse student body. Draft Report. Toronto: Ontario. Ministry of Education and Training.

Dragnea, C., \& Erling, S. (2008). The effectiveness of Africentric (black-focused) schools in closing student success and achievement gaps: A review of the literature. Etobicoke, ON: Toronto District School Board.

Egale Canada. (2005, April 18). About Egale Canada. Retrieved from http://www.egale.ca/index.asp?lang=E\&menu=2\&item $=1152$

Galabuzi, G. (2008). Making the case for an africentric alternative school. Our Schools/ Our Selves, 17, 27-32.

Gordon, M and Zinga, D. (March, 2012). "Fear of stigmatisation”: Black Canadian youths' reactions to the implementation of a Black-focused school in Toronto, Canadian Journal of Educational Administration and Policy, 131, 1-37

Government of Ontario. (2006). Safe schools policy and practice: An agenda for action. Toronto: Queen's Printer for Ontario.

Harper, H. (Spring 1997). Difference and diversity in Ontario schooling. Canadian Journal of Education, 22(2), 192-206.

Henry, F., \& Tator, C. (2006). The colour of democracy: Racism in Canadian society. 3rd Ed. Toronto: Nelson.

Hsieh, H., \& Shannon, S. E. (2005). Three approaches to qualitative content analysis, Qualitative Health Research, 15(9), 1277-1288. 
James, C. (1994). "The paradox of power and privilege: Race, gender and occupational position." Canadian Woman Studies:Race and Gender, 14 (2), 47-51.

James, Carl. (2012). Students "at risk": Stereotypes and the schooling of Black boys. Urban Education 47 (2), 464-494.

Jones, B. (2002). Critical race theory: new strategies for civil rights in the new millennium? Harvard Blackletter Law Journal, 18 (1).

Kaid, L. L. (1989). Content analysis. In P. Emmert \& L. L. Barker (Eds.), Measurement of communication behavior (pp. 197-217). New York: Longman.

Kozak, A (2009). The Ontario parent involvement policy analysis. Theses and dissertations. Paper 594. http://digitalcommons.ryerson.ca/dissertations/594.

Kymlicka, W. (1998). Finding our way: Rethinking ethnocultural relations in Canada. Toronto: Oxford University Press.

Ladson-Billings, G. (1998). Just what is critical race theory and what's it doing in a nice field like education, Qualitative Studies in Education, 11(1), 7-24.

Ladson-Billlings, G., \& Tate, W. (1995). Toward a critical race theory of education. Teachers College Record, 97(1), 47-68.

Leck, S. (2013). Teacher's college lengthened. Queen's Journal, 141(2)

Lewis, S. (1992). Report on Race Relations in Ontario (Toronto: Government of Ontario).

Mackey, E. (1999). The house of difference: Cultural politics and national identity in Canada. London: Routledge.

Maxwell, JA. (2005). Qualitative research design: An interactive approach. Thousand Oaks, CA : Sage Publications.

McConaghy T. (1993). Ontario to implement antiracist policies. The Phi Delta Kappan, 
75(2), 190-191.

Miller, H. (2013). Analyzing poverty, learning, and teaching through a critical race theory lens. Review of Research in Education, 37(1), 1-53.

Morgan, Harry. (2011). Early childhood education: History, theory and practice. Roman \& Littlefield: Lanham, Maryland

Ontario Human Rights Commission. (2003, July 8). The Ontario Human Rights Code, Retreived from http://www.ohrc.on.ca/en/ontario-human-rights-code

Ontario Ministry of Education. (2010). Ontario parent engagement policy. Retrieved from http://www.edu.gov.on.ca/eng/parents/involvement/PE_Policy2010.pdf

Ontario Ministry of Education. (2009a). Equity and inclusive education in Ontario schools: Guidelines for policy development and implementation. Toronto, ON: Queen's Printer for Ontario. Retrieved from http://www.edu.gov.on.ca/eng/policyfunding/inclusiveguide.pdf

Ontario Ministry of Education. (2009b). Realizing the promise of diversity: Ontario's equity and inclusive education strategy. Toronto, ON: Queen's Printer for Ontario. Retrieved from http://www.edu.gov.on.ca/eng/policyfunding/equity.pdf

Ontario Ministry of Education. (2009c). Policy/Program Memorandum no. 119: Developing and implementing equity and inclusive education policies in Ontario schools. Retrieved from http://www.edu.gov.on.ca/extra/eng/ppm/119.html

Ontario Ministry of Education. (2009d). Quick facts: Ontario's equity and inclusive education strategy. Retrieved from 
http://www.edu.gov.on.ca/eng/policyfunding/EquityQuickFacts.pdf

Ontario Ministry of Education. (2008). Reach every student: Energizing Ontario education. Toronto, ON: Queen's Printer for Ontario. Retrieved from http://www.edu.gov.on.ca/eng/document/energize/energize.pdf

Ontario Ministry of Education. (2006). Kindergarten Program. Toronto, ON: Government of Ontario.

Ontario Ministry of Education. (2005). Ontario parent involvement policy. Retrieved from http://wwww.edu.gov.on.ca/eng/document/nr/05.12/developing.pdf

Ontario Ministry of Education. (1993). Policy/program memorandum no. 119: antiracism and ethnocultural equity in school boards: Guidelines for policy development and implementation. Toronto: author.

Ontario Ministry of Education and Training. (1987). The development of a policy on race and ethnocultural equity. Toronto: Ontario.

Ortiz, L., \& Jani, J. (2010). Critical race theory: A transformational model for teaching diversity. Journal of Social Work Education,46(2), 175-193.

People for Education. (2008). Ontario's urban and suburban schools: A discussion paper on the schools we need in the 21st century. Retrieved from http://www.peopleforeducation.com/urban-suburban-schools

Pushor, (2007). Parent engagement, creating a shared world. Invited Research Paper:

Ontario Education Research Symposium, Toronto.

Segeren, A. \& Kutsyuruba, B. (2012). Twenty years and counting: An examination of the Development of Equity and Inclusive Education Policy in Ontario (1990-2010). Canadian Journal of Educational Administration and Policy, 136, 1-38 
Schick, C. (2010). "Whatever happened to anti-racist education?” In C. Smith, C. (Ed.). AntiRacism In Education: Missing in Action. (pp.28-47). Alberta: Canadian Centre for Policy Alternatives.

Solomon, R.P. (1997). Race, role modeling and representation in teacher education and teaching. Canadian Journal of Education, 22(4), 395-410.

Stack, C.B. (1974). All our kin: Strategies for survival in a Black community. New York: Harper and Row.

Tate, W. F. (1997). Critical race theory and education: History, theory, and implications. In M. Apple (Ed.), Review of research in education (Vol. 22, pp. 195-247). Washington, DC: American Educational Research Association.

Toronto Board of Education. (1988). Education of Black students in Toronto schools: Final Report of the Consultative Committee. Toronto: Board of Education.

Toronto District School Board. (2010). Achievement gap task force: draft report. Toronto, ON.

Weber, R.P (1990). Basic content analysis. Beverly Hills, CA: Sage.

Young, T. L. (1994). Antiracism and ethnocultural equity policies in ontario schools: An historical examination. (Order No. MM96184, University of Toronto (Canada). ProQuest Dissertations and Theses, $125-125$ p. Retrieved from http://ezproxy.lib.ryerson.ca/login?url=http://search.proquest.com/docview/304170093?a ccountid=13631. $(304170093)$. 


\title{
Appendix
}

No.119: Developing and Implementing Equity and Inclusive Education Policies in Ontario Schools

\author{
20 Ontario \\ Policy/Program \\ Memorandum \\ No. 119
}

Date of Issue: April 22, 2013 Effective: Until revoked or modified

Subject: DEVELOPING AND IMPLEMENTING EQUITY AND INCLUSIVE EDUCATION POLICIES IN ONTARIO SCHOOLS

Application: Directors of Education

Secretary-Treasurers of School Authorities

Superintendents

Principals of Elementary Schools

Principals of Secondary Schools

Principals of Provincial and Demonstration Schools

Reference: This memorandum replaces Policy/Program Memorandum No. 119, "Developing and Implementing Equity and Inclusive Education Policies in Ontario Schools", June 24, 2009. 


\section{INTRODUCTION}

Ontario's publicly funded education system supports and reflects the democratic values of fairness, equity, and respect for all. Recognizing the importance of education, the Ontario government has established three core priorities:

- high levels of student achievement

- reduced gaps in student achievement

- increased public confidence in publicly funded education

An equitable, inclusive education system is fundamental to achieving these core priorities, and is recognized internationally as critical to delivering a high-quality education for all learners. "Equity and excellence go hand in hand. ... In a truly equitable system, factors such as race, gender, and socio-economic status do not prevent students from achieving ambitious outcomes. Our experience shows that barriers can be removed when all education partners create the conditions needed for success."1

1. Ministry of Education, Ontario, Reach Every Student: Energizing Ontario Education (Toronto: Ministry of Education, Ontario, 2008), p. 8.

Providing a high-quality education for all is a key means of fostering social cohesion based on an inclusive society where diversity is affirmed within a framework of common values that promote the well-being of all citizens. Ontarians share a belief in the need to develop students' character and to prepare students for their role in society as engaged, productive, and responsible citizens. Active and engaged citizens are aware of their rights, but more importantly, they accept responsibility for protecting their rights and the rights of others.

On April 6, 2009, the Minister of Education released Realizing the Promise of Diversity: Ontario's Equity and Inclusive Education Strategy (hereafter referred to as "the strategy"). This document sets out a vision for an equitable and inclusive education system. The action plan contained in the document focuses on respecting diversity, promoting inclusive education, and identifying and eliminating

discriminatory biases, systemic barriers, and power dynamics that limit students' learning, growth, and contribution to society. These barriers and biases, whether overt or subtle, intentional or unintentional, need to be identified and addressed.

The purpose of this memorandum is to provide direction to school boards 2 on the review, development, implementation, and monitoring of equity and inclusive education policies to support student achievement and well-being. Our schools need to help students develop into highly skilled, knowledgeable, and caring citizens who can contribute to both a strong economy and a cohesive society.

2. In this memorandum, school board(s) and board(s) refer to district school boards and school authorities.

3. Others include Policy/Program Memoranda No. 108, "Opening or Closing Exercises in Public Elementary and Secondary Schools", January 12, 1989; No. 127, "The Secondary School Literacy Graduation Requirement", October 13, 2004; No. 128, "The Provincial Code of 
Conduct and School Board Codes of Conduct", December 5, 2012; No. 144, "Bullying Prevention and Intervention", December 5, 2012; and No. 145, "Progressive Discipline and Promoting Positive Student Behaviour", December 5, 2012. Sections 27-29 ("Religion in Schools") of Regulation 298 replaced No. 112, "Education about Religion in the Public Elementary and Secondary Schools", December 6, 1990.

4. Ministry of Education, Ontario, Antiracism and Ethnocultural Equity in School Boards: Guidelines for Policy Development and Implementation (Toronto: Ministry of Education, Ontario, 1993), p. 7.

\section{BACKGROUND}

The ministry has issued several policy/program memoranda to support equity, student achievement, and positive school climates, including Policy/Program Memorandum No. 119, "Development and Implementation of School Board Policies on Antiracism and Ethnocultural Equity", July 13, 1993.3 When No. 119 (1993) was issued, many boards focused on creating learning environments that respected the cultures of all students. The antiracism and ethnocultural policies contained in No. 119 (1993) went "beyond a broad focus on multiculturalism and race relations" 4 to focus on identifying and changing institutional policies and procedures, as well as individual behaviours and practices that may be racist in their impact. No. 119 (1993) sought to equip students with the knowledge, skills, and attitudes to live in an increasingly diverse world, appreciate diversity, and reject discriminatory behaviours and attitudes. Several boards have expanded these antiracism and ethnocultural policies into more inclusive equity policies that address a broader range of discriminatory factors.

In addition, it is now recognized that such factors as race, sexual orientation, physical or mental disability, gender, and class can intersect to create additional barriers for some students. Many organizations, including the United Nations, are recognizing the compounding impact of such intersections on discrimination. Ministry and board policies, therefore, should also take intersecting factors into account.

Although much has been done - and continues to be done - to build the publicly funded education system's capacity to foster equity and inclusiveness in boards and schools, evidence indicates that some groups of students continue to encounter discriminatory barriers to learning. Recent research shows that students who feel connected to teachers, to other students, and to the school itself do better academically. 5

5. D. Goleman, Social Intelligence: The New Science of Human Relationships (New York, NY: Bantam, 2006).

6. Paragraph 8(1)(29.1) of the Education Act gives the Minister of Education the authority to require all school boards to develop and implement an equity and inclusive education policy, and, if required by the Minister, to submit the policy to the Minister and implement changes to the policy as directed by the Minister.

7. Ontario Regulation 181/98, "Identification and Placement of Exceptional Pupils", requires school boards to consider placement of students with special education needs into regular classrooms before considering alternative placements. 
8. Boards should also refer to Policy/Program Memorandum No. 148, "Policies Governing Admission to French-Language Schools in Ontario", April 22, 2009; and L'admission, l'accueil et l'accompagnement des élèves dans les écoles de langue française de l'Ontario-Énoncé de politique et directives, 2009.

Policy/Program Memorandum No. 119 (2009) broadened the scope of No. 119 (1993) to take into account a wide range of equity factors, as well as all of the prohibited grounds of discrimination under the Ontario Human Rights Code and other similar considerations. No. 119 (2009) fully supported and expanded on the principles of antiracism and ethnocultural equity that were outlined in No. 119 (1993), and did not reflect a weakened or reduced commitment to antiracism or ethnocultural equity. By promoting a system-wide approach to identifying and removing discriminatory biases and systemic barriers, it has helped to ensure that all students feel welcomed and accepted in school life.

This memorandum brings No. 119 (2009) up to date so that it is in accordance with amendments to the Education Act; that is, school boards are now required to develop and implement an equity and inclusive education policy. This memorandum also updates No. 119 (2009) to reflect the fact that gender identity and gender expression are dimensions of diversity under the Ontario Human Rights Code.

\section{REQUIREMENTS FOR BOARDS}

All publicly funded school boards are required to develop, implement, and monitor an equity and inclusive education policy that includes a religious accommodation guideline, in accordance with the requirements set out in this memorandum and the strategy, and that complies with relevant legislation, including amendments to the Education Act.6

The strategy is designed to promote fundamental human rights as described in the Ontario Human Rights Code and the Canadian Charter of Rights and Freedoms, with which school boards are already required to comply, subject to subsection 93(1) of the Constitution Act, 1867, and section 23 of the Canadian Charter of Rights and Freedoms. Boards must comply with all other aspects of the Education Act and regulations made under the act, including Ontario Regulation 181/98, which pertains to students with special education needs.7 Boards must also comply with the Municipal Freedom of Information and Protection of Privacy Act, the Ontarians with Disabilities Act (2001), and the Accessibility for Ontarians with Disabilities Act (2005), as applicable. Other relevant legislation, such as the Youth Criminal Justice Act, must be referenced where appropriate. In addition, boards should refer to English Language Learners / ESL and ELD Programs and Services: Policies and Procedures for Ontario Elementary and Secondary Schools, Kindergarten to Grade 12, 2007; Ontario's Aménagement linguistique Policy for French-Language Education, 2005;8 and Ontario First Nation, Métis, and Inuit Education Policy Framework, 2007. They should also consult with their legal counsel and Freedom of Information coordinators to ensure that they are fulfilling all their legal responsibilities. 
The equity and inclusive education policy of a board must address the eight areas of focus outlined in this memorandum, and must include a guideline on religious accommodation and an implementation plan. During the cyclical process of reviewing and revising their policies, boards will take steps to align all their other policies and procedures (e.g., on safe and accepting schools, student discipline, staff hiring and development) with their equity and inclusive education policy. This process will help to ensure that the principles of equity and inclusive education are embedded in all aspects of board and school operations.

School board policies must be comprehensive and must cover the prohibited grounds of discrimination set out in the Ontario Human Rights Code. The code prohibits discrimination on any of the following

grounds: race, colour, ancestry, place of origin, citizenship, ethnic origin, disability, creed (e.g., religion), sex, sexual orientation, gender identity, gender expression, age, family status, and marital status. Boards may also address related issues resulting from the intersection of the dimensions of diversity that can also act as a systemic barrier to student learning.

\section{POLICY DEVELOPMENT}

Equity and inclusive education policies and implementation plans will be consistent with the guiding principles and goals set out in the strategy, with the requirements in this memorandum, and with the revised ministry document entitled Equity and Inclusive Education in Ontario Schools: Guidelines for Policy Development and Implementation, 2013 (hereafter referred to as "the guidelines"). These three documents should be used together when boards are reviewing and/or developing and implementing their equity and inclusive education policy, and when conducting their cyclical reviews of all their other policies.

When reviewing or developing their equity and inclusive education policy, boards are expected to consult widely with students, parents, 9 principals, teachers and other staff, school councils, their Special Education Advisory Committee, their Parent Involvement Committee and other committees (e.g., Diversity Committee; First Nation, Métis, and Inuit Education Advisory Committee), federations and unions, service organizations, and community partners in order to reflect the diversity of the community.

9. In this memorandum, parent( $s$ ) refers to parent(s) and guardian(s).

Boards have flexibility to adapt their equity and inclusive education policy to take into account local needs and circumstances.

\section{Areas of Focus}

The three goals of the equity and inclusive education strategy are as follows:

- shared and committed leadership by the ministry, boards, and schools to eliminate discrimination through the identification and removal of biases and barriers

- equity and inclusive education policies and practices to support positive learning 
environments that are respectful and welcoming to all

- accountability and transparency with ongoing progress demonstrated and communicated to the ministry and the community

In order to achieve these goals, each school board policy on equity and inclusive education will cover the following eight areas of focus.

\section{Board policies, programs, guidelines, and practices}

Through cyclical policy reviews, boards will embed the principles of equity and inclusive education in all their other policies, programs, guidelines, and practices, so that an equity and inclusive education focus is an integral part of every board's operations and permeates everything that happens in its schools.

Boards should make every effort to identify and remove discriminatory biases and systemic barriers that may limit the opportunities of individuals from diverse communities for employment, mentoring, retention, promotion, and succession planning in all board and school positions. The board's work force should reflect the diversity within the community so that students, parents, and community members are able to see themselves represented. The board's work force should also be capable of understanding and responding to the experiences of the diverse communities within the board's jurisdiction.

\section{Shared and committed leadership}

Board and school leaders must be responsive to the diverse nature of Ontario's communities. Leadership is second only to teaching in its impact on student outcomes. School boards and schools are expected to provide leadership that is committed to identifying and removing discriminatory biases and systemic barriers to learning. Specifically, boards will identify a contact person to liaise with the ministry and other boards to share challenges, promising practices, and resources.

In accordance with the principles of the ministry's Ontario Leadership Strategy, effective board and school leaders promote the development of collaborative environments in which participants share a commitment to equity and inclusive education principles and practices. This collaborative approach includes and supports the active engagement of students, parents, federations and unions, colleges and universities, service organizations, and other community partners.

\section{School-community relationships}

Schools and boards will continue building their capacity - with the active engagement of parents and school community partners - to create and sustain a positive school climate that supports student achievement and well-being. Each board and its schools should review the structures of 
existing committees and partnerships to help ensure that they reflect the principles of equity and inclusive education. Boards should expand upon their outreach efforts in order to foster new partnerships that engage a cross-section of diverse students, parents, staff, community members, and various organizations, including business groups (e.g., business education councils). Boards are encouraged to draw upon the expertise of their partners to explore innovative ways of sharing resources that can help them meet the diverse needs of their students and provide new and relevant learning opportunities. Strong, positive, and respectful relationships are necessary to effect real change so that all students can reach their potential regardless of personal circumstances.

\section{Inclusive curriculum and assessment practices}

Students need to feel engaged in and empowered by what they are learning, supported by teachers and staff, and welcome in their learning environment. To this end, boards and their schools will use inclusive curriculum and assessment practices and effective instructional strategies that reflect the diverse needs of all students and the learning pathways that they are taking. Schools must provide students and staff with authentic and relevant opportunities to learn about diverse histories, cultures, and perspectives. Students should be able to see themselves represented in the curriculum, programs, and culture of the school. Also, since schools have a pivotal role in developing the work force of tomorrow, students should be able to see themselves represented in the teaching, administrative, and support staff employed at the school.

Boards are expected to draw upon strategies that have been shown by the evidence to support student success and reduce achievement gaps. These include reviewing resources, instruction, and assessment and evaluation practices to identify and eliminate stereotypes, discriminatory biases, and systemic

barriers. For example, schools could make use of differentiated instruction, which takes into account the backgrounds and experiences of students in order to respond to their individual interests, aptitudes, and learning needs.

In order to help ensure that assessment and evaluation are valid and reliable and lead to improvement of student learning, teachers must use assessment and evaluation strategies outlined in the assessment and evaluation section of the curriculum policy documents. Assessment tasks should be designed to ensure consistency of standards, and any discriminatory biases in the way students' work is assessed and evaluated should be identified and addressed.

\section{Religious accommodation}

School board policies on religious accommodation must be in accordance with the Ontario Human Rights Code and the requirements stated in Policy/Program Memorandum No. 108, "Opening or Closing Exercises in Public Elementary and Secondary Schools", and in sections 27-29 ("Religion in Schools") of Regulation 298. As part of their equity and inclusive education policy and implementation plan, boards will include a religious accommodation guideline in keeping with the Ontario Human Rights Code, which prohibits discrimination on the grounds of creed (e.g., religion) and imposes a duty to accommodate. 
10. Under the Ontario Human Rights Code, the duty to accommodate requires accommodation to the point of undue hardship. For further details, see Ontario Human Rights Commission, Policy on Creed and the Accommodation of Religious Observances (1996), available at www.ohrc.on.ca.

11. Ontario Regulation 472/07, "Suspension and Expulsion of Pupils", identifies mitigating factors and other factors that must be taken into account in individual cases.

\section{School climate and the prevention of discrimination and harassment}

Board policies on equity and inclusive education are designed to foster a positive school climate that is free from discriminatory or harassing behaviour. A positive and inclusive school climate is one where all members of the school community feel safe, included, welcomed, and accepted. The principles of equity and inclusive education support a whole-school approach to foster positive student behaviour. These principles must also be applied in progressive discipline, particularly when it is necessary to take into account mitigating and other factors. 11 When relationships are founded on mutual respect, a culture of respect becomes the norm. Boards will also put procedures in place that will enable students and staff to report incidents of discrimination and harassment safely, and that will enable boards to respond in a timely manner.

Regular school and board monitoring of school climate is essential. Monitoring through school climate surveys, as outlined in Policy/Program Memorandum No. 144, "Bullying Prevention and Intervention", can help identify inappropriate behaviours, barriers, or issues that should be addressed. Boards are therefore expected to incorporate questions on equity and inclusive education in their school climate surveys. Boards must require schools to conduct anonymous school climate surveys of their students and staff and the parents of their students at least once every two years, in accordance with subsection 169.1(2.1) of the Education Act.

\section{Professional learning}

Professional learning activities must be ongoing, evidence-based, and focused on positive outcomes. Boards will therefore provide opportunities for teachers (including guidance counsellors), support staff, administrators, and trustees to participate in training on topics such as antiracism, antidiscrimination, and gender-based violence, and will provide information for students and parents to increase their knowledge and understanding of equity and inclusive education. Boards are also encouraged to draw upon existing expertise within their own organization, other boards, and their own community partners and agencies. Changing individual and collective behaviour, as well as organizational and institutional practices, will help to ensure that the education system is free from discrimination.

\section{Accountability and transparency}


Ongoing and open communication to keep all stakeholders informed of a board's goals and progress will increase transparency and public confidence in the board and its schools. It is expected that boards will post their equity and inclusive education policy on their website.

Board and school improvement plans, within the context of a board's strategic multi-year plan, will take into consideration the board's equity and inclusive education policy. The plans should focus on identifying and removing any barriers to student learning in order to reduce gaps in achievement and provide a respectful and responsive school climate.

Each board will post the Director of Education's annual report on its website, which will inform the ministry and the local community about the progress the board has made in meeting its strategic objectives in the previous school year and the action the board is taking in those strategic priority areas where goals are not being met.

\section{IMPLEMENTATION}

The ministry recognizes that school boards are at different stages in the implementation of an equity and inclusive education policy. The ministry expects boards to demonstrate continuous improvement, so that progress is evident on an annual basis towards the goal of embedding the equity and inclusive education policy into all operations of the board.

Implementation plans will:

- contain clearly stated annual objectives and measurable outcomes at both the board and school levels;

- reflect consultation with community partners, and show evidence of active and ongoing partnerships with students, parents, and diverse communities;

- contain indicators for measuring and evaluating progress.

\section{RESOURCES}

To support boards in developing, implementing, and monitoring their policy on equity and inclusive education, the ministry is providing practical strategies, advice, and templates in the guidelines. The ministry will also review and conduct research on promising practices in equity and inclusive education, and will disseminate this information to boards.

\section{APPENDIX: DEFINITIONS}

The following definitions are included for the purposes of this policy/program memorandum only.

Diversity: The presence of a wide range of human qualities and attributes within a group, organization, or society. The dimensions of diversity include, but are not limited to, ancestry, 
culture, ethnicity, gender, gender identity, gender expression, language, physical and intellectual ability, race, religion, sex, sexual orientation, and socio-economic status.

Equity: A condition or state of fair, inclusive, and respectful treatment of all people. Equity does not mean treating people the same without regard for individual differences.

Inclusive Education: Education that is based on the principles of acceptance and inclusion of all students. Students see themselves reflected in their curriculum, their physical surroundings, and the broader environment, in which diversity is honoured and all individuals are respected. 